\title{
Healing through Ancestral Knowledge and Letters to Our Children: Mothering Infants during a Global Pandemic
}

\author{
Miriam G. Valdovinos ${ }^{1, * \mathbb{C}}$, Noralis Rodríguez-Coss ${ }^{2} \mathbb{D}$ and Rupal Parekh ${ }^{3}$ \\ 1 Graduate School of Social Work, University of Denver, Denver, CO 80208, USA \\ 2 Women's and Gender Studies, Gonzaga University, Spokane, WA 99258, USA; rodriguez-coss@gonzaga.edu \\ 3 School of Social Work, University of Connecticut, Hartford, CT 06103, USA; rupal.parekh@uconn.edu \\ * Correspondence: miriam.valdovinos@du.edu
}

Received: 27 September 2020; Accepted: 14 December 2020; Published: 21 December 2020

\begin{abstract}
The struggle for work-life balance amongst women in academia who are both mothers and scholars continues to be apparent during a global pandemic highlighting the systemic fissures and social inequalities ingrained in our society, including systems of higher learning. Women of color professors on the tenure track are vulnerable to the intersecting ways capitalism, sexism, and racism exacerbate the challenges faced by motherscholars, making it imperative to explore these nuances. While motherscholars may share advice about navigating family leave policies or strategizing scholarship goals, no one could have prepared us for our motherscholar roles during a pandemic. We were, in some ways, unprepared for giving birth with a heightened level of social isolation and feelings of loneliness, while racial unrest and loud exigencies to protect the lives of Black, Indigenous, and People of Color (BIPOC) persist. Through three testimonios, we explore how ancestral/indigenous knowledge provides us with ways to persist, transform, and heal during these moments. We share letters written to each of our babies to encapsulate our praxis with ancestral knowledge on mothering. We reflect on matriarchal elders, constricted movement in our daily routines, and ongoing worries and hopes. We theorize this knowledge to offer solidarity with a motherscholar epistemology.
\end{abstract}

Keywords: motherscholar; Women of Color; ancestral knowledge; testimonios; global pandemic; healing; academic mothering

\section{Introduction}

New mothers usually experience social isolation and feelings of loneliness, but rarely has there been a time when a pandemic underscores the necessity of strengthening social support for them. New mothers typically self-isolate due to the overwhelming obligations associated with the care of a newborn. Additionally, new mothers find limited social options that include young children while some social invitations, like a dinner party amongst friends, require that babies stay with babysitters, which involves yet more planning and coordination. However, during the current pandemic, the possibility for these few social interactions become muted when gatherings require health symptom screenings to minimize the exposure to and spread of the novel coronavirus (COVID-19). Although, the impact of the effects of pandemic — social distancing-on the health and mental health of new mothers is yet unknown, there is literature on the adverse physical and psychological effects of social isolation and loneliness on new mothers (AXA Healthcare 2015; Rokach 2004; Qualter et al. 2015; Lee et al. 2019).

As first-time mothers and first-generation Women of Color scholars from working class families who are navigating the tenure track, we have also experienced social isolation and feelings of loneliness 
in our careers and personal lives. The struggle of work-life balance for motherscholars has only been heightened by a pandemic that underscores the systemic fissures and social inequalities deeply ingrained in our society, including higher education (e.g., Castañeda and Isgro 2013; Caballero et al. 2019). For Women of Color professors in tenure-track positions, the intersections of capitalism, sexism, and racism exacerbate the challenges faced by motherscholars. This may entail finding reliable childcare outside the home that fits an equitable pay scale within the family's budget. It may require defending our passions to pursue our career to our family members who may have had different mothering experiences. It may consist of microaggressions in collegial interactions, including maternal microaggressions (Vega 2019). We are navigating multiple systems that were not built with our interests in mind. We came together to share our testimonios and explore how ancestral/indigenous knowledge provides us with ways to persist, transform, and heal during these challenging times.

We define mothering as both an identity and experience, which is not limited to a biological account. Mothering encompasses the decision to raise and guide another human being through life. We embody this term from a visionary feminist activist stance-in the words of bell (Hooks 2000, p. 76) - by raising our babies in antisexist and antiracist environments that are part of the principles in which we live and work, understanding that this is not always a perfect model. As cisgender mothers in heterosexual and normative relationships, we also understand our privilege, yet, do not limit this term to hegemonic ideals of parenting. We use the term 'motherscholar' unhyphenated (Matias 2011) as cited in (Matias and Nishi 2018) to reflect that we are both mothers and scholars, identities which are inseparable. Our scholarship is influenced by our roles as mothers to our children. As Matias (2011) described, these roles are at the forefront of our scholarship and activist endeavors. Other motherscholars may share advice about navigating family leave policies or strategizing scholarship goals for the tenure-track expectations. Still, no one could have prepared us for giving birth with a heightened level of isolation and loneliness during a pandemic that requires distance for public health safety.

Furthermore, current racial unrest and loud exigencies to protect the lives of Black, Indigenous, and People of Color (BIPOC) ${ }^{1}$ underscores our work as motherscholars. These demands require that we identify systemic oppression and continue to dismantle the structures that perpetuate marginalization and oppression of these BIPOC communities.

We are not the first to explore issues of mothering for motherscholars of color. We add to the existing scholarship by mothers of color and queer mothers of color (e.g., Lorde 1979; Collins 1994; Glenn 1994; Moraga 1997; Ross 2009; Téllez 2011, 2013; Caballero et al. 2019) by imparting narratives of the moments that have required us to assess our positionality and challenged our beliefs, value systems, and moral stances. We share how our coping strategies have transformed into healing realizations that will influence and shape the future of our children, families, and communities. Our healing realizations turn to the memory of our ancestral past to face the challenges we face in the present and to visualize possibilities in the future, while embodying a new identity as mothers. Here, memory is a tool for survival and self-preservation.

We wrote letters to each of our babies to unpack our experiences and inform a motherscholar epistemology. We illustrated our scholar praxis, as influenced by ancestral knowledge-a connection to a person's ancestors, their ancestral homelands (place), traditions, beliefs, and assumptions. We embedded within our babies' letters some of the surprises of the motherhood journey during a pandemic as a form of connection to our infants who we believe hold the possibilities for a liberatory revolution and sustainable future. We also theorized about our matriarchal elders, constricted movement in our daily routines, and ongoing worries and hopes that emerged through our conversations. We focused on matriarchal ancestral knowledge both by choice and as a political statement. The knowledge that has been passed to us by matriarchal elders came up as we

1 We employ this acronym recognizing that the social experiences of Black and Indigenous (intentionally capitalized) communities often get lost or ignored when people of color's (POC) experiences are addressed. POC is not a monolithic identity and colorism in our communities continues to privilege light skin and anti-black ideologies. 
discussed healing and survival. This knowledge from our mothers and their mothers is often forgotten (see La Cerva 2020) or rendered silent within a heterosexist patriarchal society. Thus, the matriarchs' understanding of the world (through methods such as songs, advice giving, and meal preparation) not only gave us solace in moments of insecurity and isolation; these were moments of counter-hegemonic praxis.

We bore this process as a connection with other motherscholars navigating similar circumstances. We position ourselves as scholars, activists, daughters, sisters, mothers, wives, and women faculty of color in U.S.-based universities. We all live in different regions of the United States (Pacific Northwest, Rocky Mountains, and Northeast Coast). We are in Social Work (Miriam and Rupal) and Women's and Gender Studies disciplines (Noralis). While we share about the joys of mothering, we recognize that not all women desire to be mothers nor do all women desire to be identified by their reproductive potential. We acknowledge that mothering may evoke unexpected emotions and feelings that may present as obstacles, particularly during a pandemic. We integrate these realizations so that our narratives are not glorifying mothering, and we recognize that our identities go beyond mothering. As the saying goes: everything is difficult the first time. Mothering during a pandemic is no different.

\section{Literature Review}

\subsection{Academic Context for Motherscholars}

Women's unequal experiences balancing work and life in comparison to men have been documented by scholars for decades. From the unpaid labor women do to support the productive economy of the household (Waring 1988), to earning a salary while maintaining the workload at home, which Arlie Hochschild (1989) called the double shift, to the loss of earnings for choosing parenting instead of working, also called the "mommy tax" (Crittenden 2001). This and other women's unequal experiences in the workforce are connected to patriarchal discriminating practices where women's labor is considered less important, unnoticed, or unofficial within legitimized standards of labor (Seager 2018, p. 122).

For motherscholars, the work and life balance is complex. Due to the lack of boundaries (e.g., not "regular business" hours), the success in this profession depends on excelling in all tasks that the profession demands, while demonstrating "enormous dedication and spirit of sacrifice" (Ferrara 2020, para. 12). To be a mother and to be a scholar seem to be contradictory to each other when traditional expectations and perceptions are taken into account. On the one hand, many women in academia have learned through unspoken conventional expectations that motherhood represents itself as a threat to their career because the time spent doing reproductive labor is time that could be dedicated to teaching and advancing one's scholarship (Gonçalves 2019, p. 475; Ferrara 2020, para. 2). On the other hand, a patriarchal society normalizes, expects, and celebrates motherhood as part of women's gendered demands. This balance becomes even more complicated when one finds oneself as a motherscholar with few social and economic resources to afford childcare. In addition, motherscholars could face institutionalized obstacles to find a tenure-track job or to obtain promotion ${ }^{2}$ because of one's gender, one's decision to become a mother, or a combination or both.

A concise account of those obstacles includes both policies and practices that have been experienced and documented by single motherscholars (Fonseca-Chavéz et al. 2019). Some of these accounts address the lack of "supportive spaces," including on-campus daycare or child care subsidies; difficulty attending conferences, other professional development events, and work social events; lack of time to serve in committees; inflexibility in extending the tenure clock; and 60 to 70-h weekly workload expectation for tenure-track faculty, which "is incompatible with being an involved and present

2 In 2020, the global gender gap that exists in academia was documented by Catalyst: Workplaces that Work for Women, stating that Women are a minority among senior academics, holding an average of 34 per cent full professorships in the United States. Link: https://www.catalyst.org/research/women-in-academia/. 
mother" (Fonseca-Chavéz et al. 2019). These accounts, in addition to weak or nonexistent parental leaves, ${ }^{3}$ create conditions in which women pay what Mary Ann Manson (2013) called a 'baby penalty.' (Diem-Wille 1996). The penalty consists of mothers not competing for promotion or dropping "out of academe altogether," while men's careers improve when they have children (Manson 2013, para. 3). Baby penalties, however, can be greater for mothers who are socially impacted by multiple forms of oppression. For example, parents who do not conform to cis-heteronormative ideals are excluded from conversations relevant to parenting (Bower-Brown and Zadeh 2020; Leventry 2020), making it difficult to explore the extent to which these penalties impact their academic careers. In our work for this article, we dialogued about what it means to be not only a mother, but also face these institutionalized sexist obstacles as Women of Color.

\subsection{Unique Dynamics for Mothers of Color in Academia}

Sexist policies and practices intersect with other forms of oppression, such as racism, xenophobia, and classism. Maura I. Toro-Morn (2013) pointed out that Women of Color "play an important role in the corporate university" because "race, nationality, and gender figure prominently as tropes of the new ideology of difference and multiculturalism and as systems of exploitation and subordination" (p. 191). Enrica Maria Ferrara (2020) also theorized the dehumanizing legacy of patriarchy, which is evident in the exploitation and subordination of women of color's experience as a result of their overrepresentation in adjunct positions that normalize oppression by being poorly paid and lacking employment benefits. Oftentimes, Women of Color are pulled in multiple directions that service institution's diversity and inclusion efforts, while also being presumed and treated as incompetent (Gutierrez y Muhs et al. 2012). This reality in relationship to women of color's access to promotion is due to systemic refusals to see them as leaders and often denial of their intellectual value and contributions (Turner 2003; Blain 2018). In the United States, for example, only 7.5 percent of full-time faculty positions are occupied by Women of Color (Ryu 2010) as cited in (Harris and González 2012, p. 2), in comparison to 75 percent of the professoriate being white male and females (National Center for Education Statistics NCES). These statistics are more alarming considering that faculty of color almost entirely are employed in Historically Black Colleges and Universities (HBCUs) and Puerto Rican universities (Turner 2003, p. 113), which tend to have higher teaching loads and lower pay.

While difference and multiculturalism are fashionable identity markers for institutions, motherscholars of color experience the toll of the "baby penalty" at higher proportions than white women. Patricia Hill Collins's earlier research on Black women motherwork (1994) also named and theorized these experiences. Collins's motherwork acknowledged how the reproductive labor of mothers of color challenge white middle-class mothers' roles that assume mothers and their children enjoy economic security. Additionally, motherwork does not center individualism, instead, it recognizes that the survival of women of color's communities, including future generations, are dependent on motherwork labor (Caballero et al. 2019, p. 6). Applied to the contemporary moment, motherscholars find themselves not only experiencing pressure to demonstrate their commitment to antiracist practices, but are also grappling with how the current Black Lives Matter activism and social movements against the imprisonment of immigrant children, among other justice movements, will impact their mothering practices and their children's well-being.

While sexist and racist practices create isolation, ghettoization (restricted to segregated spaces), and higher expectations to do service assignments (Toro-Morn 2013, p. 107), as mothers, Women of Color

3 A dataset of parental leave policies in the United States and Canadian Universities reported that about $60 \%$ of institutions have some form of paid parental leave for new mothers or fathers, while $40 \%$ have no parental leave. Link: https: //aaronclauset.github.io/parental-leave/. In addition, the Organization for Economic Cooperation and Development (OECD) studied 41 industrialized nations, finding that the United States is the only country that does not have a national paid leave mandate. As of 2019, only five state-mandated parental leave plans existed in the United States. Link: https://www.pewresearch.org/fact-tank/2019/12/16/u-s-lacks-mandated-paid-parental-leave/. 
report facing the institutional barriers mentioned above in addition to racial/ethnic microaggressions adding a layer of stress and psychological harm (Caballero et al. 2019; Vasquez Heilig et al. 2019). Maternal microaggressions, as called by Christine Vega (2019), refer to the experiences of motherscholars having to "confront a unique layer of racial and gendered microaggressions" (p. 7). Amid these additional stressors, motherscholars of color defy the academy by refusing to have their bodies policed by institutions. Rather, they chose to transform them "by choosing not to hide our children [and] include them within [their] work for social justice," as stated by the Chicana M(other)work collective (Caballero et al. 2019, p. 5). In addition to the systemic inequality that persists against motherscholars of color in academia, COVID-19 has had an impact on all the identities discussed here. The following section explores this further.

\subsection{Current COVID-19 Pandemic Context}

The intersections of race, class, gender, and socioeconomic status during the COVID-19 pandemic have changed the social and economic realities of people's lives. Preliminary research on social inequalities during the pandemic suggests women of color are most at risk for losing their job, and people of color are at greater risk of COVID-related mortality (Ewing-Nelson 2020). According to the findings from the 2020 Guttmacher Survey of Reproductive Health Experiences, which measured women's sexual and reproductive health during the COVID-19 pandemic, $41 \%$ of women worried about how they were going to take care of their children as a result of the pandemic, therefore, impacting their career and economic opportunities. Furthermore, the study found women often delayed their needed in-person healthcare, potentially resulting in negative health, social, and economic consequences (Lindberg et al. 2020). Zamarro et al. (2020) found that over $44 \%$ of women, especially working mothers, suffered more job losses than men and handled significantly greater responsibility for childcare during the pandemic.

The gendered impact of the pandemic is far reaching and sheds light on some of the most alarming realities in society. The United Nations has reported that since lockdown orders were instituted, violence against women has increased, especially domestic violence, by over $30 \%$ in many parts of the world (United Nations Department of Global Communications 2020). Pre-existing inequalities, such as the lack of hand washing facilities, disproportionality impact women due to high levels of poverty among women across the globe. Estimates of global job loss in sectors with high female employment point to the impact of the pandemic on women's economic well-being.

In the wake of the COVID-19 outbreak, academics suddenly transitioned to remote learning, major household responsibilities were reallocated, and for those academics who have children, a good majority of the day was either spent homeschooling or caregiving for their young children. Unsurprisingly, the brunt of these responsibilities fell mostly on the shoulders of women. The evidence of these gendered disparities is only beginning to emerge (Alon et al. 2020). The United States remains the most impacted country by COVID-19, in part due to the overall failure of the current administration and the prioritization of the economy over people's lives, resulting in over 250,000 deaths and the disproportional burdens on women (Hernandez et al. 2020).

The impact of COVID-19 on academic women's productivity has recently become glaringly obvious. Research conducted on motherhood and productivity in academia suggests such identity has no effect on women's productivity and, in fact, it has been reported that women are even more productive after having their first child (Ward and Wolf-Wendel 2004, p. 249). In May 2020, however, an article published in The Guardian by Anna Fazackerley revealed during COVID-19, women's research production declined, while having risen for male academics. A meta-research study found that the prevalence of first-authored COVID-19 papers by women in academic medicine was 19\% lower than those published in the same journal last year (Andersen et al. 2020). Due to the fact that academics are more likely than nonacademics to have flexibility in their schedule, female academics who already bear the burden of the majority of childcare are disproportionately impacted in times of social and economic instability. 
"COVID-19 has changed not only how we (women) approach our work but also how we let work infiltrate our most intimate spaces. This, like many forms of inequality, has hit women especially hard" (Vialette 2020, para. 15). This abnormal period has shed light on the unbalanced approach to family care and work in the academic community, and the ongoing bias on parents in academia, particularly women. Equally important, are nonconventional parenting experiences that continue to fall through the cracks of these conversations. Queer, non-binary writer, Amber Leventry (2020), stated, "A pandemic may be hurting gender equality, but more than one gender is being hurt" (para. 6), naming the multiple struggles faced by non-cisgender and non-heterosexual parents. As more of this evidence emerges, and the personal and career consequences for female academics become even more evident, broader discussions on the gender-productivity gap during times of instability and crisis are critical to the overall wellbeing of female academics. Moreover, there is a critical need to advocate for policies that mitigate the discrimination and limitations faced by academic mothers and subsequently lead to long-term gender equality in a profession whose policies have historically favored males.

\subsection{Ancestral Knowledge Theoretical Framework}

"We never had any doubt that women were the centre and core of our community and our nation. No nation ever existed without the fortitude of our grandmothers, and all of those teachings have to be somehow recovered ... [young women] they've got to dig up the medicines, to heal the people. And the medicine, in this case, are the teachings. They've got to dig them up! You've got to find them."-Mosom Danny Musqua (Saulteaux elder) (Anderson 2011, p. 3)

The quote above is a reminder of why indigenous knowledge or ancestral knowledge (Smith 1999) needs to be incorporated in the ways that we theorize and understand our mothering experiences. Smith (1999) discussed the importance of using research methodologies that decolonize our understanding of how knowledge is incorporated in our research and our lived experiences. This ancestral knowledge (AK) framework differs from the westernized science and research paradigms. Further, indigenous knowledge (IK) (Cajete 2000, 2005) is knowledge that is connected to a person's ancestors as well as connection to ancestral homelands (place), along with traditions, beliefs, and assumptions that are not accounted for in positivist epistemology that assumes objectivity is better than subjective realities.

Returning to the knowledge that is passed down from the people where we originate from (ancestral lands) is imperative when we consider mothering. AK brings to consciousness how these knowledge systems and social constructs intersect with power systems (e.g., colonialism) over time (Moreno Sandoval et al. 2016). There is also a common experience, particularly in our three communities, where the effects of colonialism are evident in some of our practices (one of them being the disconnect to our matriarchal roots and the patriarchal practices that ensue). Loss of these teachings may lead to taking an interest to revitalize this knowledge. This process may also require that we remain critical of some of the AK that gets passed down in our communities. This offers us a space of reimagination to either correct some of the dubious cultural practices or a space of transformation to address the wrongdoings that we have experienced across generations, particularly our women relatives.

In this paper, we connect the AK lessons, traditions, and practices that have been passed down to us by our matriarch elders. This includes the importance of the role and representation of mothers, the intergenerational collectives built amongst women, and the birth rituals and celebration of new life. Even though the three of us represent different cultures and communities (Chicana/Mexican, Puerto Rican, and South Asian), we can trace the importance of the birthing process because this is when mothers experience being close to death as part of giving life. For instance, in many Mesoamerican indigenous cultures, women are the healers and protectors of the community and their culture (Gonzales 2012). Research on indigenous women from the has Caribbean established the existence of fertility rites where planting, for example, was associated with their physical capacity to bear children. Women being in charge of this important task that secured the community's access to food, signified high value in their role members of the community (Sued-Badillo 1989, p. 35). Mothers are the mediators of 
giving life, binding motherhood to the growth of our families and communities. Conversely, historical atrocities of women's bodies being controlled and the forced and coerced sterilization of Mexican, Puerto Rican, Black, Native American, and mentally disabled women (Gutiérrez and Fuentes 2009) have been documented and are a form of community genocide.

One of the AK lessons is to understand how our ancestors upheld women as the sacred bearers of creation, procreators of the nation state, and cultural carriers who pass down language and cultural values (Spears-Rico 2019). For Miriam, it is critical to remember that before the Spanish invasion of P'urhépecherio in 1530 (present-day Michoacán, Mexico), P'urhépecha society was matrilineal; hence, lineage, prestige, and inheritance were passed down the mother's line (Zarate-Vidal 1999). P'urhépecha women also engage in a maternalista feminism (Spears-Rico 2019), which connects activism to motherhood. This is not to downplay the issues related to women's mistreatment due to rigid masculinities that impose a toxic patriarchy.

Traditional patriarchal understandings of motherhood in Puerto Rico suggest that this role is prioritized over other identities. Thus, women's main role as mothers is to present "as sacrificed, nurturing, and dedicated mothers who prioritize the care of their children and homes over their own needs" (Rodríguez-Coss et al. 2016, p. 3). ${ }^{4}$ From a historical perspective, in Latin America and as an extension in Puerto Rico, Catholicism and colonialism has fostered this traditional view of motherhood. According to Helen I. Safa (1995), Catholicism has perpetuated this ideal "through an emphasis on family honor and female virginity" (p. 47). Honor and purity is represented through the image of Virgin Mary as the ideal model of womanhood, femininity, and motherhood. Spanish colonialism left its patriarchal print through "patria potestad or paternal authority," a colonial law that gave men (particularly white elite men) the sole legal and social authority over their wives and children (Safa 1995, p. 47). Male dominance through the Church and State have devalued women's roles as mothers for centuries. Yet, as stated by Toro-Morn (2013), "gendered tropes of 'traditionality' that defy the lived realities of Puerto Rican women" have been demystified by "Puerto Rican feminists and scholars" for decades (p. 104). Women do not necessarily define themselves by historical legacy, in part because of the advances that feminist movements have done throughout the years. At the same time, these traditional views are not completely eradicated.

"Motherhood is central to womanhood," is the salient theme that underscores the complexity of a women's role(s) in South Asian culture. In the South Asian context, the mother possesses the essential attributes fundamental to human existence and is glorified through many depictions of the female Goddess, nonetheless, her chief role is ultimately to bring into existence a male child. Sons are the potential providers of care in old age and are the keepers of wealth and property. The yearning of a male child begins soon after the wedding ceremony, where both groom and bride engage in sacrificial rituals for the hopes of a future son. Needless to say, these rituals devalue girls and women all together. Ironically, women often share this preference for sons, and gladly engage in these practices, although strong patriarchal traditions create a chup (silencing of a person) culture, often leading to women's complicit agreement with their sons and husbands. Sex-favoring cultural practices, date back as far as the Indus-Saraswati valley period during 2000 B.C. As stated by (Bhattacharji 1990) "It was obligatory; a girl was trained to be a good wife and a good mother and was blessed with "the motherhood of sons" (p. 1).

Gender inequality continues to be pervasive in modern India, and the Indian diaspora, which refers to people from India who live outside of their country of origin. The recent public acts of rape in Delhi, India and accounts of modern sexism in the workplace is juxtaposed with women being employed in large numbers and laws changing to favor women's inheritance of property. The irony is made clear when Narayan (2018) distinctly draws our attention to the hypocrisy that often leads to death of unborn girls- "We worship goddess, but murder unborn girls by the hundreds of thousands" (p. 9).

4 The 2019 Race and Ethnicity in Higher Education: A Status Report by Lorelle L. Espinosa, Jonathan M. Turk, Morgan Taylor, and Hollie M. Chessman also stated that up until 2016, faculty of color were less likely than white faculty to hold full professorships. 
At the same time, more and more South Asian women are demanding change and do not want their patronized legacy to shape their futures. Although Indian states are not interested in protecting women, South Asian female scholars and activists (e.g., Mohanty 2003; Nagar and Collective 2006; Sen 2012), much like their Chicana and Puerto Rican counterparts, are on the forefront of change, systematically breaking down antiquated systems of oppression.

\section{Methodological Decisions}

We situated our testimonio as a part of a critical race methodological stance (Delgado Bernal et al. 2012; Pérez Huber 2009; Blackmer Reyes and Curry-Rodríguez 2012). In this form, testimonio is a tool for women of color to theorize oppression, resistance, and subjectivity (Latina Feminist Group 2001). Testimonios are guided by the narrator's will to share events that we viewed as significant to recount our situation's importance (Yudice 1991). We were most interested in centering our stories to benefit other motherscholars, especially those who are also first-time mothers during this pandemic. While sharing our individual stories, our motivations and intentions were very deliberate: (1) to offer support to one another as first-time mothers and (2) to speak about the ways in which we honor the strengths that emerge from our ancestral knowledge that is shared amongst our families, communities, and cultures as a way to provide healing during this extended quarantine period tied to a global pandemic. It is our hope that these reflections will resonate with other motherscholars. Through our narratives, we demonstrated a focus on a "collectively experienced reality" (Brabeck 2003, p. 253) rather than only an individual one. Being rooted in storytelling is significant because it is a tool for cultural survival.

The letters emerged during the summer (after maternity leave) as an attempt to create meaning of motherhood during a pandemic, and before the academic term began in the fall 2020. Over the course of four months, we engaged in a series of bi-monthly discussions and a reflective process, where we shared our postpartum concerns, anxieties of mothering, and worries about our families' health. These reflections resulted in our testimonios that we incorporated in the letters to our children. Through an iterative process, we offered each other support to complete these letters because the writing process was difficult. This was a key moment to reflect about what it meant to begin the academic year with a new identity as mothers, but also teaching during the pandemic. The letters to our babies are our standpoint as motherscholars of color, and our activism in preserving joy and love, which academia tends to undermine. The letters became a space of possibility between us and our babies where joy and love prevailed over all neoliberal, capitalist, and neocolonial impositions-ideas that children will be a distraction to fulfill our academic duties, that joy and love do not belong in the spaces where we work.

Letter writing as a method has been used to document transnational motherhood experiences, as well as those of mothers in prison (e.g., Hondagneu-Sotelo and Avila 1997; Madianou and Miller 2011; Mignon and Ransford 2012; Loper and Tuerk 2011). Even though for some of us, transnational motherhood or mothering from prison are experiences in our families' histories, we are personally removed from these realities. The simplicity of the technology of using pen and paper (and its permanence) versus other forms of documenting bring a sentimental connection to sharing experiences with those far away from us who are oftentimes unable to be closer. In the letters to our children, we incorporated our testimonios as a form of transcending the academic writing process and offering a moment of solidarity with other motherscholars to illustrate the tensions and beauty of what it is to survive and thrive in these contexts.

We recognized our relationalities (Wilson 2008) as we live with one another across time and space. We built on the interconnectedness of our struggles and our victories as first-time motherscholars by describing our experiences as we theorized and felt our stories. The work of motherscholars cannot be categorized into boxes, especially in the current moment where most of our lives, if not all, are happening in our homes. Spears-Rico (2019) reminded us, "Motherwork becomes part of our intersectionality, as mothering and motherhood permeate our homes, writing and pedagogy." (p. 258) Through this process, we nurtured and witnessed each other's physical, emotional, intellectual, 
and spiritual health as we have navigated systems of oppression and dignified our experiences in the academy. We did not intend to solidify absolute resolutions but rather give space to share about the processes and to bring our three stories into dialogue. It is our hope that these narratives will go beyond sustaining us, moving into a decolonial space in the academy for us to stay accountable to an alterNATIVE (centering the connection to ancestors and ancestral homelands) epistemological stance.

\section{Findings}

In writing letters to our infants, we began to see similarities in our stories and reflections that in various ways connected to ancestral knowledge. Three themes will be incorporated (one before each letter) to include some of the critical reflections that emerged in our testimonios.

\subsection{Our Familial Matriarchs}

In this process, it became evident that we are shaped and inspired by some of the cultural practices, rituals, and the lives of our elder matriarchs (i.e., mothers, grandmothers, great-grandmothers). In our cultures, the connection to grandparents is critical as they play a significant role in some of the rituals and cultural practices that accompany the birth of a new grandchild. We all live in various distances from many of our family members, including the grandmothers of our children. This meant that for our parents to meet our children, they had to rely on airplane travel. All our children were born a few weeks before stay at home orders, travel restrictions, and growing public health concerns because of the increase on COVID-19 cases in the United States. Therefore, all the grandmothers (and some of the grandfathers) travelled to meet their grandchildren.

We appreciated the moments of comfort that came from this ancestral wisdom, especially during this pandemic. Rupal reflected, when she first became a mother, she found comfort in the vartao (stories/tales) of her mother, grandmother, and aunts. These stories became something she sought out on a daily basis, particularly during the quarantine and social distancing. A daily FaceTime call with her mother would consist of "how my mom and grandmother would do things as a mother." At first Rupal dismissed "their ways," as old antiquated child rearing practices, but she soon learned the wisdom and strength behind every word, every varta.

During their visits, the grandmothers/abuelitas/bas were integral in assisting with new baby responsibilities, e.g., diaper changing, bathing baby, household chores, meal preparation, and sharing matriarchal stories that were not always a part of our narratives growing up. As Noralis reflected on her relationship with the women in her family, she saw how it shaped who she is as both a woman and a mother. She acknowledged the good fortune to have been loved by her mother, grandmothers, and aunties that their care and attention gave her self-confidence to face the world and maneuver the challenges that a patriarchal society brings with it. Their hopes to see her grow up to be a better version of themselves were evident in the stories they told her about themselves, most of the time highlighting the social limitations that prevented them from doing certain things in life. These stories carried a tone of nostalgia and sorrow, from tales of extreme poverty to the nuisance of getting married and falling into the tedious social demands of being women, mothers, daughters, and wives. Stories that tended to advise, "por eso tienes que estudiar, para que no dependas de ningún hombre" (this is why you have to study, so that you do not depend on any man).

Sometimes moments of tension emerged, especially if there were certain aspects of our motherhood experience that were not typical or similar to that of our mothers. For example, the work expectations in our full-time careers may look different to what our mothers experienced, either as mothers who were solely responsible for the care of the baby (stay at home mamas) or working part-time and having more flexibility with their work schedules to accommodate caring for the baby. The concept of self-sacrifice is central to a traditional South Asian woman's identity (in Latinx cultures too), often a source of pride by both the woman and the husband and his family. Any deviation from the role of doting mother and devoted wife resulted in being outcasted from society. Even when the AK wisdom was not applicable for our individual mothering experiences in the current context, deconstructing 
those larger value systems, tradition, and rituals related to birth and motherhood were essential to also consider how culture and traditions need to give space to what is needed as we evolve across time. This may include a new pattern where our husbands are more involved in childcare responsibilities or seen as different when they embrace those responsibilities.

\section{FIRST BABY LETTER}

My dear baby Lorenzo Enrique:

I write this letter as I watch you concentrate playing with your toys, working on controlling the movement of your little hands, and struggling while pushing your legs so that you can reach out for things better. I stop writing to tell you how grateful I am to have you in my life and kiss you while you smile. I have been grateful ever since the day I knew you were in my womb. Your dad and I waited hundreds of days with excitement to become your parents, and you choose us! I sang and smiled while touching my belly, imagining your face, loving you deeply even before your existence.

As you get to know me better, you will learn about the significance that all the women in your family have in my life. You will get to see how their stories shaped me and how I made of this life a journey that included you in connection to them, mostly because they are your roots, tus raices, and while roots do not necessarily define who we are, they prepared a path for us through work, cares, and hopes of a world where you could exist. While their path prepared me to have you, nothing could have prepared me for a global pandemic that would outbreak just weeks before your birthday. None of them have been through a situation like this one, but this is when roots are important because they help us maneuver difficulties. Here I tell you how two of your ancestral mothers' companionship helped me during the first days of your birth and how I see their lives present in your future.

As you kept growing inside me, your great grandmother, my abuela Justina, left the physical world and I could not travel to Puerto Rico to be with our family because you were just recently in my belly and I did not want to put the pregnancy at risk. The day she passed away, I envisioned myself in the future showing you pictures of her and talking to you about the wonderful woman she was. Abuela Justina would have loved to meet you, but instead, she decided to accompany me in the journey of receiving you to this planet. I saw her smiling in my dreams. As I planned my stay at the hospital for your birth, I wanted to bring things with me that friends and family have given for our first hours together: an omamori amulet from Japan, a rosary from the Vatican City, and an ancestral amulet, una mano de figa, sent from Puerto Rico. I saw the same faith and energy that the people that gave those objects to me had in them, but I also brought the gift of your abuela's presence next to me as I pushed, and eventually holding my hand when a doctor cut my belly during the cesarean that welcomed you to the world. Even in the moments of fear, I never doubt her light was guiding and preparing me for your arrival.

As soon as I could have you on my chest and hold you, your eyes locked with mine and this was so powerful to me, it was as if you were telling me "there you are! Look, here I am!" Since then, I feel I have the most privileged and difficult job of all, to guide you through this life as much as you allow me to do it. One of the ways I do this is by singing to you the same lullaby that my abuela Claudina sang to me. Just as I finished writing this letter, she left the physical world and it was not possible for you to travel and meet her due to the pandemic. However, abuela was a wise woman and she sent me a message through a song I heard just hours before her death, not knowing that day her heart would stop beating. She used to sing that song to me when I was your age and at that moment I sang it to you. These songs are a part of our rituals, and I recite them to you in honor to your great grandmother's love, a love in which I rejoiced, a love that now extends to you with the same warmth and sense of protection that once snuggled me.

As you fall asleep on my shoulder, I think about that love that earlier generations gave to my grandmother and this love that I give you and that you will pass to your loved ones. More importantly, I sing to you in español, once the oppressor language in the land where I was born, and now the language of my resistance to be close to home despite the geographical distance, so that you feel 
identified with the place where I come from, an attempt for you to find yourself in the mountains, rivers and oceans that have nurtured me since I was born. I sing to you echoing the voices of those women that are my home and that love you as much as I do:

\author{
Una mariposita que del cielo bajó \\ A little butterfly that came down from the sky \\ Con sus alas tendidas y en el pico una flor \\ With its wings spread out and a flower in its beak. \\ ¿Para quién son las flores si no son para mí? \\ For who are the flowers if they're not for me? \\ Ay mamita de mi alma, yo me muero por ti, por ti. \\ Oh, dearest mama, I'm dying for you, for you
}

I hope that by hearing my voice you realize that your voice also matters. Your first cry made me the happiest person on earth. Your voice searched for air with such a strength announcing your arrival to our lives. And now, as I hear your cooing sounds, it makes me hopeful to think that your generation will have a voice like no other.

The world, as you will know it is unknown to me, but I will work hard to help you face anything with self-confidence and courage. At the time in which I write these lines, societies struggle to find out what it means to survive a pandemic amid the systems in place that prioritize the economy over human lives. Thus, love is my way to protect you from everything I do not know. My main wish is that by the time you read this letter, I have taught you enough so that you can navigate the social realities that will emerge from this pandemic as well as other realities yet unknown to me. I am referring to your self-love and your love for those that surround you. I am referring to advocating for yourself and recognize your privileges in order to use them for other voices to be heard. I am referring to remembering where your ancestras come from as an extension of who you are in order to know where to go next and see possibilities of who you can be. May your presence continue spreading happiness to many as it does today. May your voice be at the service of social justice everywhere you go.

My love for you is to see you grow to be the person you want to be.

\title{
4.2. Movement Restrictions
}

Giving birth just before the COVID-19 shutdown occurred required us to figure out ways to have our family members present when we live far away from our immediate and extended families. Grocery shopping and a walk at the park, for example, have become things that require planning and precautions, particularly for us as mothers of infants that are in the process of strengthening their immunity system. When the pandemic began, we made decisions about the protocols to follow in order to prevent all members of the house from getting infected with the virus. In our conversations, it was discussed how we would buy things of first necessity online or selecting a person in the household to run errands for the family. In the case of having to go for a doctor's appointment or another reason, one would not have contact with the baby until after taking a shower as a preventative measure.

As the summer began and our bodies have healed more from giving birth, the walks at the park that we have dreamt about taking with our babies became a risk. We decided to walk our babies around our neighborhoods, instead of places where we would encounter more people. This, however, was not an option for all of us as we all lived in different regions that were also affected differently by the pandemic. If living in a metropolitan city, as it was the case for Rupal, walking outside represented a risk too. This made Rupal travel from New York to Oklahoma to stay with her family in search of support. Certainly, we recognize the privilege of having a roof where we could protect ourselves from having to interact with others, but going through postpartum knowing that we could not visit or receive visits from our friends and family suddenly felt an enormous restriction. We have experienced first-hand how much of our personal growth and professional success depended on a "village" of 
people. During the pandemic, there was no village to support us in raising our babies. The care of our children became a difficult task without the help of our support systems.

Months have passed since the pandemic began and our babies have grown. Anxiety was present as we began to work on a new academic year, some of us remotely from home, others teaching hybrid courses. Two of us decided not to visit our family because of the distance involved. The uncertainty of not knowing when we will reunite with our families causes much affliction because we feel much is lost. Moments together are lost. The place we call home holds much of our sense of identity and these restrictions of movement affect how we relate to the land and the spaces where we live. Part of our indigenous and native roots are connected to the land, so these restrictions change our relationship with the land as well. These circumstances have made it necessary for us to dive deeper into our ancestral wisdom to allow us to envision a more hopeful future during these precarious times.

\section{SECOND BABY LETTER}

To my dearest first born, Malik

I write this letter with a genuine hope that you will read it more than once in your lifetime.

You emerged from my womb into this physical world four weeks before we were expecting you to arrive. The full moon in February 2020 (Snow MOON) showered us with its radiant glow four days after your birth and it reminded me that even on the coldest of nights, beauty surrounds us. I hope your psyche will remember the soft lullabies that I sang to you when I would visit you in the NICU every night. After five days in the hospital's NICU, we brought you home during one of the biggest snowstorms Denver experienced during the winter of 2020. It was freezing outside and your dad had to focus on the road because the snow would not stop falling; yet you were sound asleep and the Denver frigid weather did not seem to bother you a bit, you were already showing us your strength. During this time, COVID-19 was just a distant occurrence in Wuhan, China, so we still did not have any idea of how this virus was going to affect us in the U.S.

[Redacted sacred story] It is important to share about your ancestors as well as reminding you about the significance of your name and offering advice for your ongoing existence in this world, a world that I have never known, so it feels necessary during these precarious times.

You were "Baby Boy" for a couple days before dad and I named you. We had various lists and with your early arrival, we were still thinking about the "perfect" name for you. Once we began to get to know you, we knew your cognomen. Never forget the significance of your name: you are a KING and a mighty force [Redacted naming ceremony specifics]. Along with your name's significance, it is important for us to have a part of you planted in your birth place- [Redacted private ritual story]. Regardless of where you reside, because your parents tend to be wanderers, you will always be connected to your birthplace.

I want to pass on to you what the previous generations of your lineage have worked through because we build upon their struggles and victories. By acknowledging their lessons, we also gather our strength. As a Black Chicano, you are blessed with beautiful African roots. These roots go deep and they also come with painful histories of great-great-grandparents who were transported to the United States and enslaved. Never forget this: transported and enslaved (but not broken). Society will try to tell you that this history does not matter because it was a long time ago; it still matters as it shapes our current reality. Know that the strength and persistence of your ancestors made it so that your grandparents, your father, your aunties and cousins, and now you too stand proudly in your royalty and lineage (listen to HiiiPower by Kendrick Lamar). Continue to embrace and embody that you are young, gifted, and Black (Nina Simone- PRESENTE!).

You are also blessed with vibrant Mexican indigenous roots from my side of the family tree. Even though there is silence around some of their struggles, I promise you that we will continue to explore their lives to better understand the lessons from their experiences. For instance, both of my grandmothers (your great-grandmothers) had intense mothering experiences which I have heard through oral stories. Abuela Remedios passed away giving birth to her eighth baby (leaving your 
abuelito Jorge without a mama at the age of four). Abuela Maria passed away when I was 16-years old. Doctors said her cause of death was a heart attack: she passed away of heartache when she learned that her first-born had taken his last breath. All this is important because relational accountability is critical for our survival and the existence of future generations to come (your children and grandchildren). Seven generations in our stories.

Here is some of my mama guidance that I want to offer you to prepare you for your life journey. This feels necessary especially as we are living through a global pandemic as well as witnessing this country trying to have deeper conversations about systemic racism and institutional oppressions that have impacted many of your kin. Mortality is one of the few things guaranteed in life (we all die one day), but the context we are living during your infancy gives me a sense of urgency to formally document this advice because a long life is not guaranteed to anyone. This is difficult because I am attempting to prepare you for a world yet to come, a world I do not know, so I hope that these next suggestions you continue to embrace as you see fit in your future.

Always remember: you were born with EVERYTHING you need to survive, it is within you. Contrary to what we may assume about parenting, none of us really know what we are doing because we are caring for a little unique being. However, when I witness your persistence to breathe from your belly, to cry when you need something, and to suckle when you need nourishment- I realize that you were born to THRIVE. With that said, remember your energy centers within your body (there are seven). Keeping these balanced and healthy will help your well-being and healing. I have experienced the imbalance and pain during periods of my life and it is not fun. Please remember it is important to: be secure and grounded; be happy and creative; be confident and stand in your power; experience joy and peace; communicate your needs; stay connected to your wisdom and intuition; and speak from your truth and awareness.

As a final note, I ask you to always trust and respect the four elements of life: water, fire, earth and wind (our way to honor our ancestors and Mother Earth). This will help you stay connected across time, place, space, and the metaphysical. I hope you are connected to what nourishes you and as part of our indigenous roots I offer the four possibilities to honor the four directions.

North-Honoring your elders and living a life that will also inform the elder that you will become. *I wish I had learned this as a child though it is never too late to practice and learn.

East-Honoring the men warriors who endured so much for us to be here. Daily movement that is intentional to nourish your breathing and grounding your energy will be essential.

West-Honoring the women warriors who also ensured so much and are often the healers of our people. Tend to your garden, pay attention to the sunshine as well as all the elements that work together to cultivate our food/nourishment. WATER is LIFE!

South-Honoring the babies, the youth, the future, the possibilities. Always make room for joy which will include laughter, singing, meditation and other forms that you will gravitate towards as you continue to grow (perhaps musical lyrics and musical instruments).

You will always be loved unconditionally by your parents and we will reflect through your piercing eyes- esos ojos que enamoran- this deep love forever. I love you my son. We continue in our ceremony of life, always- until the dream ceases to exist.

\subsection{Ongoing Worries and Hopes}

The writing process of this paper was happening alongside the preparation for the new academic year. The anxieties and uncertainties of the new time management expectations associated not only with being first-time motherscholars but also preparing to teach during this COVID era. Prior to our return to teaching we asked ourselves "Do I quit?" We were unsure of how we could manage being mothers and do our academic work amid a pandemic. We felt some part of these two identities will suffer with higher consequences than in "normal" times. We were and continue to be concerned about our health in a different way, especially if our universities are planning for on-campus classes. We are 
working from home more frequently than pre-COVID and the balancing of home life and work life is becoming more elusive, as these two things are occurring in the same spaces of our kitchen tables, living rooms, bedrooms, home offices (if we are lucky), and baby play areas.

Our conversations have reminded us that our infants continue to grow, faster than any parent expects, so there will always be ongoing worries and hopes for our little human beings. This includes concerns with returning to work, childcare, generational awareness, and required change. We discussed, for example, concerns about how this pandemic could impact our children's social skills. Being so young and not able to interact with family and friends, we wondered how they will manage social encounters in the future, such as parties and playtime with other children. Some of our worries also include the physical and mental health of us as new mothers. The postpartum period during a pandemic has meant that are usual activities to maintain physical activity and strengthen our bodies back after pregnancy are limited.

There is hope that the babies are growing up during a moment where many things are changing, so their futures may offer new ways to engage with the pertinent issues being discussed during this historical context. We hope that, when times comes, our babies adjust themselves to new social environments and could enjoy the presence of the people we love. We hope to see them smile and be affectionate with others other than their parents. We also hope to teach them enough tools for them to survive and be true to themselves. We hope that they use these tools to voice their own desires and hopes without fear of being silenced or facing dangerous consequences. Overall, we wish for their happiness.

Recently, Miriam was asked how she was doing and responded, "all the women in me are tired". It was the best way to describe how she was feeling, but she was not sure what she was trying to convey with this statement. She was invoking generations of pain, rage, and fatigue. Even if she never physically met some of my wombyn elders, somewhere deep inside her core, she felt and knew that she was not the first one in her lineage experience difficult moments such as what we are living. She grieves the collective struggle, but it gives her hope because it reminds her that we have the tools that we need to survive (and hopefully to thrive).

\section{THIRD BABY LETTER}

To my dear Chandni (moonlight)

You were born the week the "earthshines" - sunlight reflects from the Earth onto the dark side of the moon, slightly illuminating it. As you very well know, your name in Sanskrit means moonlight. And just like the moonlight controls our Earthly tides, bodies of water, and the seasons; you, my dear, have full control over our hearts.

In your short time on this Earth—gestation to 6 months of life-you have helped your mama and papa gain some needed perspective about the things that really matter in life; you have given new life to grandparents who are entering the latter stages of life; and you have helped me cry less and laugh more during these challenging times.

As I share your birth story with you, the echoes of your ba's and dadi's that have not entered your life physically but are relevant to your formation can be heard. These women will serve as your anchors, a refuge in difficult times, and a springboard to launch your dreams.

You were born on 26 February 2020 - two weeks prior to our lives entering a phase we call the "new normal." You were supposed to share your birthday (your due date) with Long Island dada (paternal grandfather) but you had different plans. Your birthday was a scheduled inducement; the doctor insisted being born on the 39th week was the most optimal for geriatric mamas with gestational diabetes like myself. I was hesitant to oblige, but your papa convinced me that following doctors' orders was the way to go. So, I begrudgingly agreed to a February 25th induction date. Little did I know that you were looking out for me. Because you decided to make your debut a few days before I hoped you would be born-this mama was eligible for an additional extension on her tenure clock, and most importantly, I was able to spend a few extra bonus days with you, my love. 
When you arrived at our small Brooklyn apartment, your entire family was waiting for you. We all shared in the joy of the birth of the first girl in the Parekh/Bhansali immediate families. Ba and dada (maternal grandparents) had already made their way to Brooklyn from Tulsa. Ba, in her usual style was all on board, really a second mama to you. She bathed you, sang her Allahgori Gujarati nursery rhymes, and gave the best hugs, as grandmothers tend to do. Ba was clearly your favorite person, and my heart was full every time I saw the both of you together. The similarities were uncanny, like two peas in a pod-the perfect match.

On the other hand, our bond developed over time; you were this beautiful girl that I never dreamed of having, but somehow you had fulfilled all my desires the moment you were born. It was a beautiful blooming relationship and I was excited to explore the world with you. But, suddenly, those family get-togethers, the dreams of gallivanting through the city streets with you came to a sudden halt. Two weeks after your birth, we were under lockdown orders to curtail the spread of COVID-19. Your paternal grandparents (dadi and dada) began to visit you with their masks on and through a window, we had to make the difficult decision to send ba and dada back to Tulsa, Hindu customs that are considered critical to the well-being of a newborn were overlooked, and our 4-generation maternal family photo is now a distant dream.

Nevertheless, a silver lining appeared three months into the pandemic-you had all your three month shots, and papa insisted we make the journey to see ba and dada in Tulsa, Oklahoma. This was a 30-hour trip, and naturally, I was hesitant and unsure your tiny 3-month-old body could handle such a massive trip. As we drove half way across the country, I watched you mesmerized by the changing landscape, my worries of you being an only child began to dissipate. I knew at the moment, you found a kindred spirit with your maternal great grandmother, who trailblazer her and her son's way to the US from the Fiji Islands after her son was brutally beaten in a military coup that left him severely disabled. She independently arranged for their departure and arrival in the US and found a way to provide treatment and care for her adult son who had suffered a severe brain injury. All without speaking a word of English.

Although none of us were prepared for this type of complexity in our lives, I am confident your spirit will meet the challenges of today's world. I will do my best to guide you and give you advice as this historical mark will be part of your legacy. My advice to you is to keep your ears and heart open. You will grow up hearing your peer's stories of lost lives, dreams, and hopes during these challenging times. You will learn how our family lost 4 relatives to COVID-19. This, my love, will be a lot to take in but several generations prior to your arrival have walked the path of uncertainty and survived to tell the story, and I am confident these vartao (stories) will make way into your heart and be a source of strength in times of adversity. As a final note, always remember, you mark the present with your contributions, your past is shaped by the women and men that came before you, and don't forget to create a future your mama can only visit in her wildest dreams. I love you to the moon and back, Chandni.

\section{Conclusions}

Even with the complexities, mothering can be a process of interconnectedness, and that is what it has offered us. We have shared moments of connection to lessen the heaviness of the loneliness that may be experienced during these times. Through this process, we were reminded of the importance of relational accountability (Wilson 2008), connection, and collegial support from other women of color motherscholars. As Indigenous and Native scholars have illustrated in previous research (e.g., Moreno Sandoval et al. 2016), we also explored some of our family epistemologies and collective memories specific to motherhood as methods for reconnecting to accountability systems as well as our ancestral homeland(s). Through these AK teachings, we considered the decolonial process (rediscovery and recovery, mourning, dreaming, commitment, and action) (Smith 1999; Laenui 2000). Even when our ancestral and cultural practices are murky and do not offer a wider spectrum of how to have an expansive experience of mothering, the decolonial process pushes us to dream and reimagine how this knowledge will be retained and reconfigured to offer larger possibilities to embrace the complexities of these roles. It honors the stories, while also giving space for renewal, change, and possibility. 
For interdisciplinary motherscholars of color who entered motherhood during a global pandemic and time in history where we are called upon to help eradicate anti-Black violence and colorism oppression (e.g., Smith 2020), it is ever so pressing for us to take action. This tremendous responsibility is juxtapositioned between the time given to us to bond with our young child (maternity leave) and the ever-growing pressure of thoughtfully responding to the inequalities faced by the most vulnerable of populations. Thus, we are coming up with new ways to stay productive during the COVID-19 pandemic, such as maximizing the work day hours (every minute counts), finding time to work when babies are sleeping, collaboratively writing with others (like in this project), and reaching out to our support systems to navigate personal and professional duties. We are grateful to have a platform, to write, and to have a job that we love. We acknowledge, the many women around the world are aching to contribute, to work and create more spaces where their voices can be heard. We recognize our privilege, but also are aware of the complexities that our positionality brings to not only ourselves, but also to our families. Most importantly, we are well aware that our voices are necessary, almost critical, at times when women's rights globally continue to be challenged. As we grabble with the emotional and mental load of motherhood and the pandemic fatigue, we share with women across the globe; we are grateful for the ancestral knowledge and wisdom that our mothers, grandmothers, and female mentors bestowed upon us.

It is imperative for us to not romanticize motherhood. In fact, we recognize the complexity of how our relationships with the women of our family sometimes can be the most challenging because of the expectations tied to motherhood. We also recognize that such complexity is connected to heteropatriarchal systems prevalent in our societies and how parents/caretakers believe that they are in charge of passing the rigorous socialization that places us in an inferior position since we are girls/female bodies. Feminist and anti-racist education gave us freedom through critical thought and this is the knowledge that allowed us to imagine different possibilities for us and for our babies. This is the wisdom that we bring to our classrooms, and this erudition travels with us as we carry our identities, our communities, and our children wherever we go.

In some ways, the stories shared in the baby letters and reflections were censored, not just because we intended to share this paper amongst our academic circles, but also because certain parts of our stories are considered sacred and as such need to remain private. Some sections of our reflections, conversations, and letters were not included for these reasons. Our ancestral knowledge continues to provide us with ways to persist, transform, and heal as motherscholars during these precarious moments. As motherscholars, we leverage the strengths from the ancestral knowledge that is shared amongst our communities, families, and cultures as a way to provide healing during this extended quarantine period tied to a global pandemic. Recognizing the interconnectedness to the struggles of the elders and the younger generations is encouraged. The letters to our babies capture some of these struggles and ways in which we offer hope.

As we write these lines, we have expressed significant concerns adapting ourselves to work while keeping a strong relationship with our children and being able to attend to their needs. The lack of or how we manage time is an inescapable reality, especially, when our work continues to demand so much from us (and we are passionate about activism and scholarship). Yet, our new mother role reminds us that we are individuals as well, so we will continue to nourish and support each other. The writing of this paper brought us together to share our testimonios, and it brought us together to be one another's social support system, which is direly needed during these times. Our letters to our babies are our act of resistance (or a resilient act) and we are reminded by our elders: if we are written into the books, we are not forgotten. Our stories will live in perpetuity, and serve as guiding lights for the babies as they grow.

Author Contributions: M.G.V led the conceptualization of mothering in academia along with the theoretical framework and testimonio methodology. N.R.-C. led the literature review sections related to the context for mothers in academia as well as unique context for Women of Color motherscholars. R.P. led the context related to COVID-19 pandemic. All three authors contributed equally to the ancestral knowledge mothering sections as well as the conclusion. All three authors also contributed to the analysis of the reflection themes (with first and second 
author taking lead to review and revise). All the authors contributed to the writing and editing of the multiple drafts of this paper in preparation for the final manuscript submission. All authors have read and agreed to the published version of the manuscript.

Funding: This research received no external funding.

Acknowledgments: We thank our children Malik Ausar Smith, Lorenzo Enrique Rodríguez, and Chandni Parekh-Bhansali for without all of you these experiences would not exist. We acknowledge our mothers Juana Valdovinos Sanchez, Norma I. Coss Torres (and Gloria J. Ramos Reyes), and Jyoti Parekh. We offer special gratitude to all the grandmothers' spirits who continue to illuminate our dreams. We honor the lives of Justina Rodríguez, Claudina Torres, Remedios Magállon, Maria Ruíz, and Hariganga and Saraswati Parekh, whose memory is present in this project. Thank you to our amiga-colega Monica De La Torre for her invaluable editorial support and to Kenia Rivera (graduate student research assistant) for her feedback. Mil gracias to our fem-mentor Ángela B. Ginorio for giving us the extra motivation and love to pursue this project, which has become our labor of love.

Conflicts of Interest: The authors declare no conflict of interest.

\section{References}

Alon, Titan, Matthias Doepke, Jane Olmstead-Rumsey, and Michele Tertilt. 2020. The Impact of COVID-19 on Gender Equality. (No. w26947). Cambridge: National Bureau of Economic Research.

Andersen, Jens Peter, Mathias Wullum Nielsen, Nicole. L. Simone, Resa E. Lewiss, and Reshma Jagsi. 2020. Meta-Research: COVID-19 medical papers have fewer women first authors than expected. Elife 9: e58807. [CrossRef] [PubMed]

Anderson, Kim. 2011. Life Stages of Native Women: Memory, Teachings, and Story Medicine. Winnipeg: University of Manitoba Press.

AXA Healthcare. 2015. Social Isolation Putting First-Time Mums at Risk. Available online: https://www.axappphealthcare.co.uk/health-worries/pregnancy---childcare/article/social-isolationputting-new-mums-at-risk/ (accessed on 25 September 2020).

Bhattacharji, Sukumari. 1990. Motherhood in Ancient India. Economic and Political Weekly 25: WS50-WS57.

Blackmer Reyes, Kathryn, and Julia E. Curry-Rodríguez. 2012. Testimonio: Origins, terms and resources. Equity $\mathcal{E}$ Excellence in Education 45: 525-38.

Blain, Keisha N. 2018. Power Is Still Too White: All Women Do Not Wield Power Equally. The Chronicle of Higher Education. Available online: https://www.chronicle.com/article/what-its-like-to-be-a-woman-in-theacademy/ (accessed on 24 September 2020).

Bower-Brown, Susie, and Sophie Zadeh. 2020. "I guess the trans identity goes with other minority identities": An intersectional exploration of the experiences of trans and non-binary parents living in the UK. International Journal of Transgender Health. [CrossRef]

Brabeck, Kalina. 2003. Testimonio: A strategy of resistance, cultural survival, and building solidarity. Feminism Psychology 13: 252-58. [CrossRef]

Caballero, Cecilia, Yvette Martínez-Vu, Judith Pérez-Torres, Michelle Téllez, Christine Vega, and Ana Castillo. 2019. The Chicana M(other)work Anthology: Porqué Sin Madres No Hay Revolución. Tucson: University of Arizona Press.

Cajete, Gregory. 2000. Native Science: Natural Laws of Interdependence. Santa Fe: Clear Light.

Cajete, Gregory. 2005. Spirit of the Game: An Indigenous Wellspring. Durango: Kivaki Press.

Castañeda, Mari, and Kirsten Isgro, eds. 2013. Mothers in Academia. New York: Columbia University Press.

Collins, Patricia Hill. 1994. Shifting the center: Race, class, and feminist theorizing about motherhood. In Mothering: Ideology, Experience, and Agency. Edited by Evelyn Nakano Glenn, Grace Chang and Linda Rennie Forcey. London: Routledge, pp. 45-65.

Crittenden, Ann. 2001. The Price of Motherhood: Why the Most Important Job in the World is Still the Least Valued. New York: Metropolitan Books.

Delgado Bernal, Dolores, Rebeca Burciaga, and Judith Flores Carmona. 2012. Chicana/Latina testimonios: Mapping the methodological, pedagogical, and political. Equity and Excellence in Education 45: 363-72. [CrossRef]

Diem-Wille, Gertraud. 1996. Femininity and professionalism: A psychoanalytic study of ambition in female academics and managers in Austria in Good. In Austrian Women in the Nineteenth and Twentieth Centuries: Cross-Disciplinary Perspectives. Edited by David F. Good, Margarete Grandner and Mary Jo Maynes. New York: Berghahn Books. 
Ewing-Nelson, Claire. 2020. After a full month of business closures, women were hit hardest by April's job losses. In Fact Sheet. Washington: National Women's Law Center, Available online: https://nwlc-ciw49tixgw5lbab. stackpathdns.com/wp-content/uploads/2020/05 (accessed on 26 September 2020).

Ferrara, Enrica M. 2020. Baby Matters: Gender Politics Beyond COVID-19 and the "Aunts" of Academia. Academic Matters: Ocufa's. Journal of Higher Education. Available online: https://academicmatters.ca/baby-mattersgender-politics-beyond-covid-19-and-the-aunts-of-academia/ (accessed on 13 September 2020).

Fonseca-Chavéz, Vanessa, Trisha Martínez, Joan Doris, and Christina S. Wilson. 2019. In Their Own Words: Single Mothers in Academia on What Really Works and What We Need to Know. Medium. Available online: https://medium.com/national-center-for-institutional-diversity/in-their-own-words-fa940dc9b98a (accessed on 13 September 2020).

Glenn, Evelyn N. 1994. Social constructions of mothering: A thematic overview. In Mothering: Ideology, Experience, and Agency. Edited by Evelyn Nakano Glenn, Gracie Chang and Linda Rennie Forcey. London: Routledge, pp. 1-32.

Gonçalves, Kellie. 2019. 'What are you doing here, I thought you had a kid now?' The stigmatisation of working mothers in academia-A critical self-reflective essay on gender, motherhood and the neoliberal academy. Gender and Language 13: 469-87.

Gonzales, Patricia. 2012. Red Medicine: Traditional Indigenous Rites of Birthing and Healing. Tucson: University of Arizona Press.

Gutiérrez, Elena R., and Lisa Fuentes. 2009. Population control by sterilization: The cases of Puerto Rican and Mexican-Origin women in the United States. Latino(a) Research Review 7: 85-100.

Gutierrez y Muhs, Gabriella, Yolanda Flores Niemann, Carmen G. González, and Angela P. Harris, eds. 2012. Presumed Incompetent: The Intersections of Race and Class for Women in Academia. Boulder: University Press of Colorado.

Harris, Angela P., and Carmen G. González. 2012. Introduction. In Presumed Incompetent: The Intersections of Race and Class for Women in Academia. Edited by Gabriella Gutierrez y Muhs, Yolanda Flores Niemann, Carmen G. González and Angela P. Harris. Boulder: University Press of Colorado, pp. 1-16.

Hernandez, Sergio, Sean O'Key, Amanda Watts, Byron Manley, and Henrik Pettersson. 2020. Tracking Covid-19 Cases in the US. Available online: https:/www.cnn.com/interactive/2020/health/coronavirus-us-maps-andcases/ (accessed on 24 November 2020).

Hochschild, Arlie R. 1989. The Second Shift: Working Parents and the Revolution at Home. New York: Viking.

Hondagneu-Sotelo, Pierrette, and Ernestine Avila. 1997. "I'm Here, but I'm There": The meaning of Latina transnational motherhood. Gender and Society 11: 548-71. [CrossRef]

Hooks, Bell. 2000. Feminism is for Everybody: Passionate Politics. Boston: South End Press.

La Cerva, Gina Rae. 2020. My mother's hands [Audio podcast]. Emergence Magazine, October 20.

Laenui, Poka. 2000. Processes of decolonization. In Reclaiming Indigenous Voice and Vision. Edited by Marie Battiste. Vancouver: UBC Press, pp. 150-60.

Latina Feminist Group. 2001. Telling to Live: Latina Feminist Testimonios. Durham: Duke University Press.

Lee, Katharine, Konstantina Vasileiou, and Julie Barnett. 2019. 'Lonely within the mother': An exploratory study of first-time mothers' experiences of loneliness. Journal of Health Psychology 24: 1334-44. [CrossRef] [PubMed]

Leventry, Amber. 2020. The Pandemic Is Impacting Trans \& Non-Binary Parents Too, So Include Us in the Conversations. ScaryMommy. November 6. Available online: https://www.scarymommy.com/pandemicimpacting-transgender-parents-too/ (accessed on 6 December 2020).

Lindberg, Laura, Alicia VandeVusse, Jennifer Mueller, and Marielle Kirstein. 2020. Early Impacts of the COVID-19 Pandemic: Findings from the 2020 Guttmacher Survey of Reproductive Health Experiences. New York: Guttmacher Institute.

Loper, Ann B., and Elena H. Tuerk. 2011. Improving the emotional adjustment and communication patterns of incarcerated mothers: Effectiveness of a prison parenting intervention. Journal of Child and Family Studies 20: 89-101. [CrossRef]

Lorde, Audre. 1979. Man child: A Black lesbian feminist's response. Conditions: Four 2: 30-61.

Madianou, Mirca, and Daniel Miller. 2011. Crafting love: Letters and cassette tapes in transnational Filipino family communication. South East Asia Research 19: 249-72. [CrossRef]

Manson, Mary Ann. 2013. The Baby Penalty. The Chronicle of Higher Education. Available online: https: //www.chronicle.com/article/the-baby-penalty (accessed on 13 September 2020). 
Matias, Cheryl. 2011. Cheryl Matias, PhD and Mother of Twins: Counter Storytelling to Critically Analyze How I Navigated the Academic Application, Negotiation, and Relocation Process. Division G-Social Context of Education/Section 2. New Orleans: American Educational Research Association (AERA).

Matias, Cheryl E., and Naomi W. Nishi. 2018. ParentCrit epilog. International Journal of Qualitative Studies in Education 31: 82-85. [CrossRef]

Mignon, Silvia I., and Paige Ransford. 2012. Mothers in prison: Maintaining connections with children. Social Work in Public Health 27: 69-88. [CrossRef]

Mohanty, Chandra T. 2003. “Under western eyes” revisited: Feminist solidarity through anticapitalist struggles. Signs: Journal of Women in Culture and Society 28: 499-535. [CrossRef]

Moraga, Cherríe. 1997. Waiting in the Wings: Portrait of a Queer Motherhood. Ithaca: Firebrand Books.

Moreno Sandoval, Cueponcaxochitl D., Rosalva Mojica Lagunas, Lydia T. Montelongo, and Marisol Juárez Díaz. 2016. Ancestral knowledge systems: A conceptual framework for decolonizing research in social science. AlterNative: An International Journal of Indigenous Peoples 12: 18-31. [CrossRef]

Nagar, Richa, and Sangtin Writers Collective. 2006. Playing with Fire: Feminist thought and Activism through Seven Lives in India. Minneapolis: University of Minnesota Press.

Narayan, Deepa. 2018. Chup: Breaking the Silence about India's Women. New Delhi: Juggernaut Books.

National Center for Education Statistics (NCES). 2020. Characteristics of Postsecondary Faculty. Available online: https://nces.ed.gov/programs/coe/indicator_csc.asp (accessed on 18 December 2020).

Pérez Huber, Lindsay. 2009. Disrupting apartheid of knowledge: Testimonio as methodology in Latina/o critical race research in education. International Journal of Qualitative Studies in Education 22: 639-54. [CrossRef]

Qualter, Pamela, Janne Vanhalst, Rebecca Harris, Eske Van Roekel, Gerine Lodder, Munirah Bangee, Marlies Maes, and Maaike Verhagen. 2015. Loneliness Across the Life Span. Perspectives on Psychological Science 10: 250-64. [CrossRef]

Rodríguez-Coss, Noralis, Ángela B. Ginorio, and Shirley J. Yee. 2016. Feminist Street Performances in Puerto Rico: Alternative Imaginaries Shifting the Ideal(ized) National Body. Doctoral dissertation, University of Washington, Seattle, WA, USA.

Rokach, Ami. 2004. Giving life: Loneliness, pregnancy and motherhood. Social Behavior and Personality: An International Journal 32: 691-702. [CrossRef]

Ross, Luana. 2009. From the "F" word to indigenous/feminisms. Wicazo Sa Review 24: 39-52. [CrossRef]

Ryu, Mikyung. 2010. Minorities in Higher Education: 24th Status Report. Washington: American Council on Education.

Safa, Helen I. 1995. The Myth of the Male Breadwinner: Women and Industrialization in the Caribbean. Boulder: Westview Press.

Seager, Joni. 2018. The Women's Atlas. London: Penguin Books.

Sen, Atreyee. 2012. Martial Tales, Right-Wing Hindu Women, and "History Telling" in the Bombay Slums. In South Asian Feminisms. Edited by Ania Loomba and Ritty A. Lukose. Durham: Duke University Press, pp. 75-95.

Smith, Linda T. 1999. Decolonizing Methodologies: Research and Indigenous Peoples. London: Zed Books Ltd.

Smith, Maya Angela. 2020. Black Motherhood amidst Two Pandemics: A Lament for My Unborn Son. Available online: https://medium.com/@MayaAngelaSmith/black-motherhood-amidst-two-pandemics-d78be408f0dd (accessed on 10 August 2020).

Spears-Rico, Gabriela. 2019. Decolonial P'urhépecha Maternalista Feminist Motherwork and Pedagogy: Birthing the Red Woman. In The Chicana Motherwork Anthology. Edited by Cecilia Caballero, Yvette Martinez-Vu, Judith Pérez-Torres, Michelle Téllez and Christine Vega. Tucson: University of Arizona Press, pp. $243-61$.

Sued-Badillo, Jalil. 1989. La Mujer Indígena y su Sociedad. Rio Piedras: Editorial Antillana.

Téllez, Michelle. 2011. Mi Madre, Mi Hija y Yo: Chicana Mothering through Memory, Culture and Place. In Latina/Chicana Mothering. Edited by Dorsía Smith Silva. Ontario: Demeter Press, pp. 57-67.

Téllez, Michelle. 2013. Lectures, evaluations, and diapers: Navigating the terrains of Chicana single motherhood in the academy. Feminist Formations 25: 79-97. [CrossRef]

Toro-Morn, Maura I. 2013. Threads that Bind: A Testimonio to Puerto Rican Working Mothers. In Mothers in Academia. Edited by Mari Castaneda and Kirsten Isgro. New York: Columbia University, pp. 100-10.

Turner, Caroline S. 2003. Incorporation and Marginalization in the Academy: From Border toward Center for Faculty of Color? Journal of Black Studies 34: 112-25. [CrossRef] 
United Nations Department of Global Communications. 2020. UN Supporting 'Trapped' Domestic Violence Victims during COVID-19 Pandemic. Available online: https://www.un.org/en/coronavirus/un-supportingtrapped-domestic-violence-victims-during-covid-19-pandemic (accessed on 25 September 2020).

Vasquez Heilig, Julian, Isabell Wong Flores, Alicia E. Barros Souza, Joseph Carlton Barry, and Selene Barceló Monroy. 2019. Considering the ethnoracial and gender diversity of faculty in United States college and university intellectual communities. STCLH Hispanic Journal of Law \& Policy 1: 1-31.

Vega, Christine. 2019. Strolling and Straddling Academic Boundaries: Chicana, Latina, and Indigenous Motherscholars in the Academy. Doctoral dissertation, University of California, Los Angeles, CA, USA.

Vialette, Aurélie. 2020. Colleges' Sexist Scandal. The Chronicle of Higher Education. Available online: https://community.chronicle.com/news/2393-colleges-sexist-scandal?cid=VTEVPMSED1 (accessed on 13 September 2020).

Ward, Kelly A., and Lisa Wolf-Wendel. 2004. Academic Motherhood: Managing Complex Roles in Research Universities. The Review of Higher Education 27: 233-57. [CrossRef]

Waring, Marilyn. 1988. If Women Counted: A New Feminist Economics. New York: Harper \& Row.

Wilson, Shawn. 2008. Research is Ceremony: Indigenous Research Methods. Nova Scotia: Fernwood Publishing.

Yudice, George. 1991. Testimonio and postmodernism. Latin American Perspectives 18: 15-30. [CrossRef]

Zamarro, Gema, Francisco Perez-Arce, and Maria Jose Prados. 2020. Gender Differences in the Impact of COVID-19. Working Paper. Available online: https://tinyurl.com/CESRGenderDiffs (accessed on 26 September 2020).

Zarate-Vidal, Margarita. 1999. Somos Indios de Papel. In Bajo el Signo del Estado. Edited by José Eduardo Hernández. Zamora: El Colegio de Michoacán, pp. 113-25.

Publisher's Note: MDPI stays neutral with regard to jurisdictional claims in published maps and institutional affiliations. 